\title{
ANALISIS DAN VISUALISASI HOST LIBURAN SINGKAT MENGGUNAKAN PENDEKATAN ANALISIS GEOSPASIAL
}

\author{
Irwan Setiawan ${ }^{1}$ \\ ${ }^{1}$ Jurusan Teknik Komputer dan Informatika Politeknik Negeri Bandung \\ Email: 1 irwan@jtk.polban.ac.id
}

\begin{abstract}
Abstrak
Perkembangan sharing economy yang terjadi secara eksponensial telah mengubah sektor akomodasi pada industri pariwisata dan perhotelan. Pengalaman pelanggan yang bervariasi, fasilitas, dan ragam harga yang ditawarkan telah menjadikan model bisnis ini menjadi salah satu alternatif layanan akomodasi tradisional dan menjadi primadona dikalangan wisatawan. Perkembangan teknologi informasi yang semakin pesat memfasilitasi banyak platform daring yang menyediakan layanan penyewaan properti dengan konsep sharing economy. Hal ini menjadikan industri pariwisata dan perhotelan menjadi kaya akan data. Penelitian ini bertujuan untuk menganalisis data iklan penyewaan properti yang berfokus pada layanan liburan singkat dengan studi kasus data Airbnb di Singapura. Hasil penelitian diharapkan dapat dimanfaatkan oleh pemain baru ataupun pemain lama dalam bisnis tersebut sebagai salah satu pertimbangan analisis situasi untuk mengambil keputusan. Analisis dilakukan untuk mendapatkan pola dan hubungan dari data yang terkait dengan harga, tipe ruangan, dan sebaran properti dalam bentuk diagram dan peta. Penelitian ini menggunakan pendekatan visual data analysis dengan menggunakan bahasa pemrograman Python.
\end{abstract}

Kata Kunci: sharing economy, visual data analysis, analisis geospasial, penyewaan properti, liburan singkat

\begin{abstract}
The development of sharing economy that happened exponentially has changed the accommodation sector in the tourism and hospitality industry. The varied customer experience, facilities, and range of prices offered has made this business model an alternative to traditional accommodation services and is a favorite among tourists. The rapid development of information technology facilitates many online platforms that provide property rental services with the concept of sharing economy. This makes the tourism and hospitality industry rich in data. This study aims to analyze data on property rental advertisements focusing on short vacation services with a case study of Airbnb data in Singapore. The results of the study are expected to be used by new players or old players in the business as one of the considerations of situation analysis for making decisions. The analysis was carried out to obtain patterns and relationships from data related to prices, room types, and property distribution in the form of diagrams and maps. This study uses a visual data analysis approach using the Python programming language.
\end{abstract}

Keywords: sharing economy, visual data analysis, geospatial analysis, property rental, shorttime vacation

\section{PENDAHULUAN}

Sharing Economy merupakan suatu model bisnis baru yang mengubah sektor akomodasi pada industri pariwisata dan perhotelan (D. Wang and Nicolau 2017). Pertumbuhan sharing economy yang terjadi secara eksponensial disebabkan oleh 
semakin berkembangnya bisnis penyewaan akomodasi yang menyediakan beragam fasilitas properti dengan harga yang beragam serta pengalaman pelanggan yang lebih bervariasi dibandingkan dengan akomodasi tradisional seperti hotel (D. Wang et al. 2016). Sharing economy pada industri perhotelan dan pariwisata yang paling populer adalah berbagi properti melalui platform daring (Yeager et al. 2019).

Dengan semakin berkembangnya teknologi informasi, banyak layanan berbasis daring yang mendukung kegiatan sharing economy seperti Airbnb, Clickstay, Booking.com, dan TripAdvisor. Teknik analisis data dapat digunakan untuk mengetahui hubungan dan pola dari data yang nantinya dijadikan bahan untuk pengambilan keputusan. Salah satu teknik analisis data adalah visualisasi data dimana data ditampilkan dalam bentuk grafik atau lokasi geografis. Penelitian yang menggunakan teknik analisis data secara visual telah banyak dilakukan. Sebagai contoh, analisis data review (Li et al. 2016; Gu et al. 2018), analisis aktifitas yang berasal dari kalender (E. Wang, Cook, and Hyndman 2020), dan distribusi akomodasi (Lagonigro, Martori, and Apparicio 2020; Ioannides, Röslmaier, and van der Zee 2019).

Pada penelitian ini, digunakan teknik analisis data secara visual untuk menganalisis profil dan pola data dari iklan penyewaan properti. Analisis dilakukan terhadap harga sewa, tipe properti, dan sebaran properti. Studi kasus yang digunakan pada penelitian ini adalah data iklan penyewaan properti di Singapura yang menyewakan propertinya untuk wisata yang tidak lebih dari 3 hari (short time vacation) (Chen, $\mathrm{Fu}$, and Lehto 2016).

\section{METODE}

Analisis dilakukan melalui lima tahapan pengerjaan. Seperti dapat dilihat pada Gambar 1, tahap awal analisis adalah penentuan tujuan analisis. Analisis dilakukan untuk mendapatkan profil data pengguna Airbnb di Singapura yang menyewakan propertinya untuk liburan singkat berdasarkan harga sewa, tipe properti, dan sebaran properti.

Tahap kedua adalah pengambilan data yang relevan dengan kebutuhan tujuan analisis. Penelitian ini menggunakan data yang diambil dari website Insideairbnb. Pada website Insideairbnb terdapat data host Airbnb dari berbagai negara, namun tidak ada data untuk host Airbnb di Indonesia. Negara terdekat dengan Indonesia yang datanya tersedia adalah Singapura. Sehingga pada penelitian ini digunakan data iklan penyewaan properti Airbnb di negara Singapura. Dari data yang tersedia terdapat 7.857 baris (listing) dan 106 kolom (atribut). Untuk kebutuhan analisa, digunakan 16 atribut seperti yang ditunjukkan pada Tabel 1.

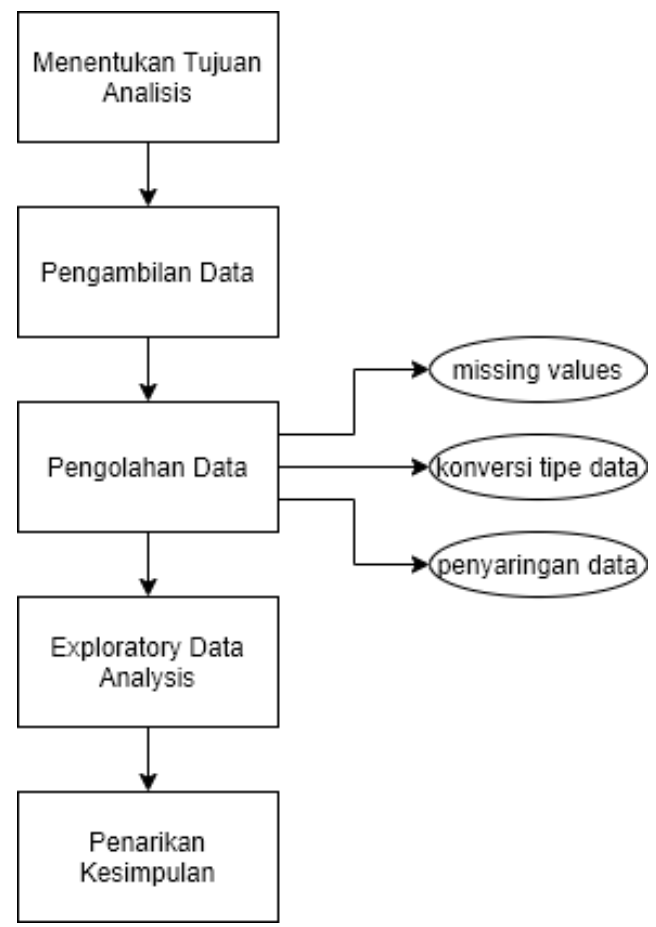

Gambar 1 Metode Analisis

Tahap ketiga adalah pengolahan data. Tujuan dari pengolahan data adalah untuk mempersiapkan data agar siap dianalisis. Pengolahan data dilakukan dengan menggunakan aplikasi Jupyter Notebook dengan bahasa pemrograman Python. Pada tahapan ini dilakukan pemeriksaan dan penanganan terhadap missing values dan tipe data serta penyaringan data yang tidak relevan untuk kebutuhan analisis.

Tahap keempat adalah exploratory data analysis. Pada tahap ini dilakukan penyajian data secara visual menggunakan aplikasi Jupyter Notebook dengan bahasa pemrograman Python. Berbagai atribut yang relevan dengan tujuan analisa dieksplorasi secara visual untuk mendapatkan pola atau anomali dari data dengan menggunakan library folium dan plotly. 
Tahap terakhir adalah penarikan kesimpulan. Pada tahapan ini disimpulkan temuan-temuan yang didapatkan pada tahapan sebelumnya.

Tabel 1 Daftar Kolom yang Digunakan

\begin{tabular}{|l|r|c|}
\hline \multicolumn{1}{|c|}{ Nama Kolom } & $\begin{array}{c}\text { Jumlah } \\
\text { Non-null }\end{array}$ & $\begin{array}{c}\text { Tipe } \\
\text { Data }\end{array}$ \\
\hline host_id & 7.857 & int64 \\
\hline host_since & 7.853 & object \\
\hline host_is_superhost & 7.853 & object \\
\hline neighbourhood_cleansed & 7.857 & object \\
\hline $\begin{array}{l}\text { neighbourhood_group_cl } \\
\text { eansed }\end{array}$ & 7.857 & object \\
\hline latitude & 7.857 & float64 \\
\hline longitude & 7.857 & float64 \\
\hline property_type & 7.857 & object \\
\hline room_type & 7.857 & object \\
\hline amenities & 7.857 & object \\
\hline price & 7.857 & object \\
\hline extra_people & 7.857 & object \\
\hline minimum_nights & 7.857 & int64 \\
\hline maximum_nights & 7.857 & int64 \\
\hline number_of_reviews & 7.857 & int64 \\
\hline cancellation_policy & 7.857 & object \\
\hline
\end{tabular}

\section{HASIL DAN PEMBAHASAN}

\section{Pengolahan Data}

Berdasarkan struktur data pada Tabel 1, terdapat missing value pada dua kolom dan tipe data yang tidak sesuai dengan isi datanya. Penanganan missing value pada kolom host_since dan host_is_superhost dilakukan dengan penghapusan data yang bernilai NULL dikarenakan hanya terdapat empat data saja dan tidak akan mengganggu hasil analisa. Untuk kolom price dan extra_people dilakukan penghapusan karakter " \$" pada data dan tipe data diubah menjadi float sedangkan host_since tipe datanya diubah menjadi date.

Tabel 2 menunjukkan data statistik awal untuk kolom bertipe int64 (selain host_id). Dikarenakan tujuan analisa lebih ditujukan untuk penyewaan properti untuk liburan singkat, maka dilakukan penghapusan data yang memiliki nilai minimum_nights $>3$ hari. Seperti dapat dilihat pada kolom price, terdapat harga sewa properti dengan harga 0 . Data tersebut ditangani dengan penghapusan data yang memiliki nilai price $=0$. Berkenaan dengan nilai maximum_nights, penulis menghilangkan data dengan nilai lebih besar dari 1.125 hari ( \pm 3 tahun). Hasil pengolahan data ditunjukkan pada Tabel 3. Banyaknya data yang akan dianalisa adalah 4.430 .

Tabel 2 Data Statistik Awal

\begin{tabular}{|c|r|r|r|r|r|}
\hline & \multicolumn{1}{|c|}{ price } & \multicolumn{1}{c|}{$\begin{array}{c}\text { extra } \\
\text { people }\end{array}$} & \multicolumn{1}{c|}{$\begin{array}{c}\text { minimum } \\
\text { nights }\end{array}$} & \multicolumn{1}{c|}{$\begin{array}{c}\text { maximum } \\
\text { nights }\end{array}$} & $\begin{array}{c}\text { number } \\
\text { of } \\
\text { reviews }\end{array}$ \\
\hline count & $7.853,00$ & $7.853,00$ & $7.853,00$ & $7.853,00$ & $7.853,00$ \\
\hline mean & 169,39 & 15,52 & 18,46 & 939,81 & 13,66 \\
\hline std & 323,97 & 21,83 & 45,41 & $1.202,18$ & 30,99 \\
\hline min & 0 & 0 & 1,00 & 1,00 & 0 \\
\hline $\mathbf{2 5 \%}$ & 66,00 & 0 & 1,00 & $1.124,00$ & 0 \\
\hline $\mathbf{5 0 \%}$ & 120,00 & 10,00 & 3,00 & $1.125,00$ & 2,00 \\
\hline $\mathbf{7 5 \%}$ & 198,00 & 25,00 & 14,00 & $1.125,00$ & 11,00 \\
\hline max & $10.000,00$ & 404,00 & $1.000,00$ & $100.000,00$ & 345,00 \\
\hline
\end{tabular}

Tabel 3 Data Statistik Setelah Pengolahan Data

\begin{tabular}{|c|r|r|r|r|r|}
\hline & \multicolumn{1}{|c|}{ price } & \multicolumn{1}{c|}{$\begin{array}{c}\text { extra } \\
\text { people }\end{array}$} & \multicolumn{1}{c|}{$\begin{array}{c}\text { minimum } \\
\text { nights }\end{array}$} & \multicolumn{1}{c|}{$\begin{array}{c}\text { maximum } \\
\text { nights }\end{array}$} & \multicolumn{1}{c|}{$\begin{array}{c}\text { number } \\
\text { of } \\
\text { reviews }\end{array}$} \\
\hline count & $4.430,00$ & $4.430,00$ & $4.430,00$ & $4.430,00$ & $4.430,00$ \\
\hline mean & 176,29 & 15,40 & 1,80 & 920,28 & 18,64 \\
\hline std & 380,20 & 21,90 & 0,80 & 411,06 & 37,47 \\
\hline min & 14,00 & 0 & 1,00 & 1,00 & 0 \\
\hline $\mathbf{2 5 \%}$ & 66,00 & 0 & 1,00 & $1.125,00$ & 0 \\
\hline $\mathbf{5 0 \%}$ & 117,00 & 10,00 & 2,00 & $1.125,00$ & 3,00 \\
\hline $\mathbf{7 5 \%}$ & 201,00 & 25,00 & 2,00 & $1.125,00$ & 19,00 \\
\hline $\mathbf{m a x}$ & $10.000,00$ & 404,00 & 3,00 & $1.125,00$ & 345,00 \\
\hline
\end{tabular}

\section{Exploratory Data Analysis}

Gambar 2 menunjukkan sebaran properti berdasarkan wilayah. Terdapat lima wilayah di Singapura, yaitu East Region, Central Region, West Region, North Region, dan North-East Region. Central Region merupakan wilayah yang memiliki jumlah properti paling banyak, yaitu sebanyak $80 \%$ dari total listing yang ada di Airbnb Singapura. Sedangkan North Region merupakan daerah dengan jumlah yang paling sedikit, yaitu $2,5 \%$.

Gambar 3 menunjukkan jumlah sebaran properti berdasarkan kelompok lokasi menggunakan library folium. Pada peta ini dapat dilakukan zoom-in dan zoom-out untuk menelusuri lokasi properti. 
Gambar 4 menunjukkan sebaran harga berdasarkan kelompok harga. Warna menunjukkan kelompok harga sedangkan ukuran lingkaran menunjukkan harga sewa dari properti tersebut.
Gambar 5 menunjukkan sebaran properti berdasarkan tahun dan Gambar 6 menunjukkan sebaran properti berdasarkan tipe ruangan.

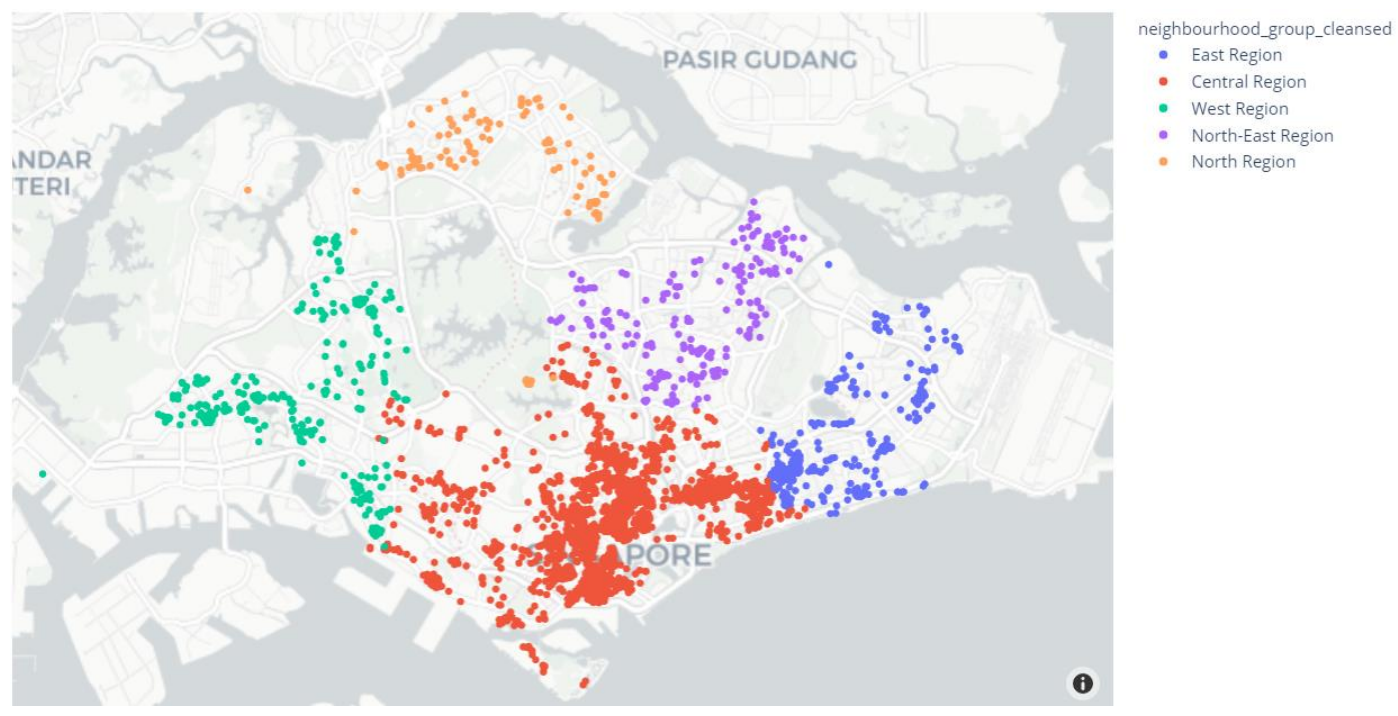

Gambar 2 Sebaran Harga Berdasarkan Wilayah



Gambar 3 Sebaran Properti Dalam Jumlah 


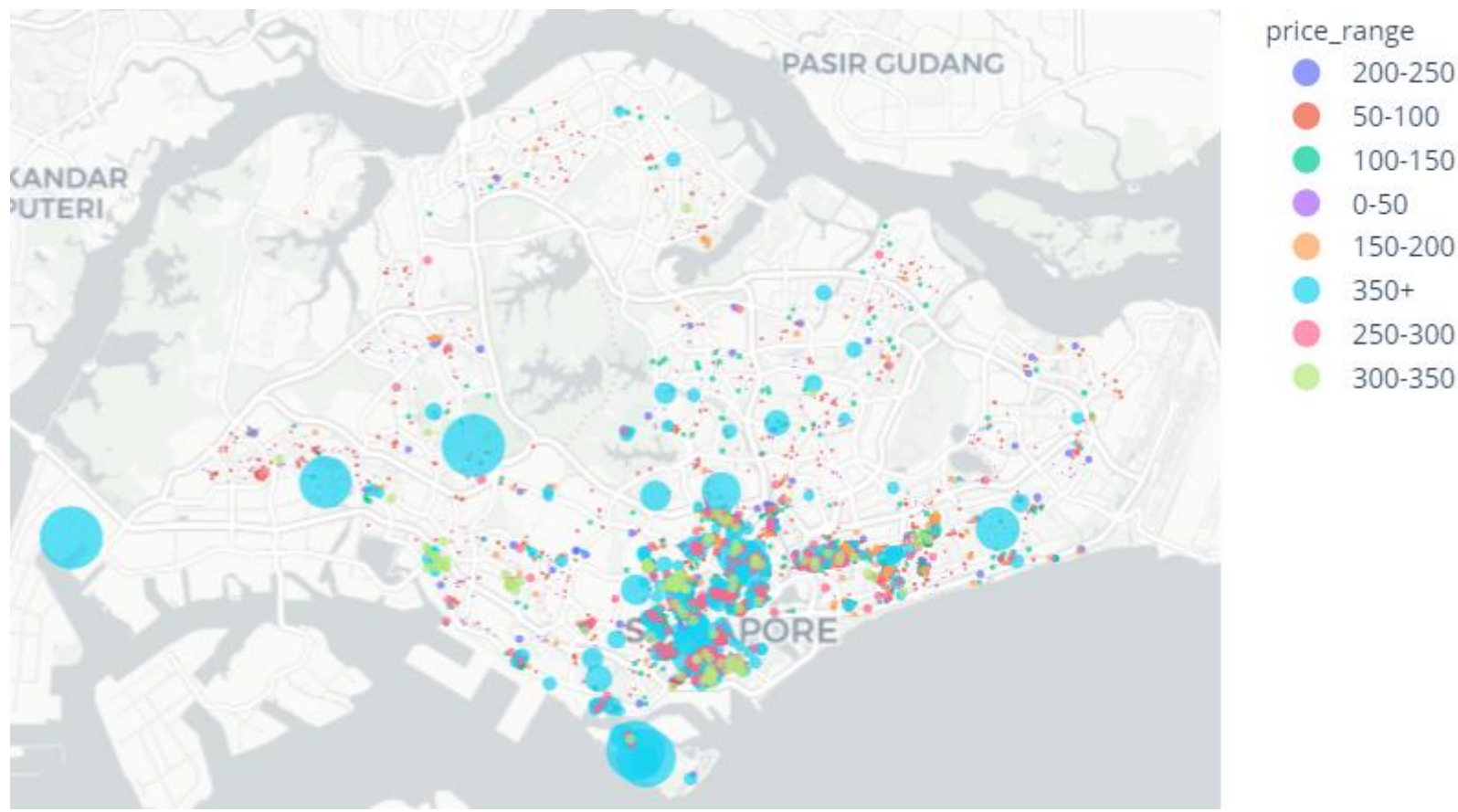

\section{Gambar 4 Sebaran Harga Sewa}
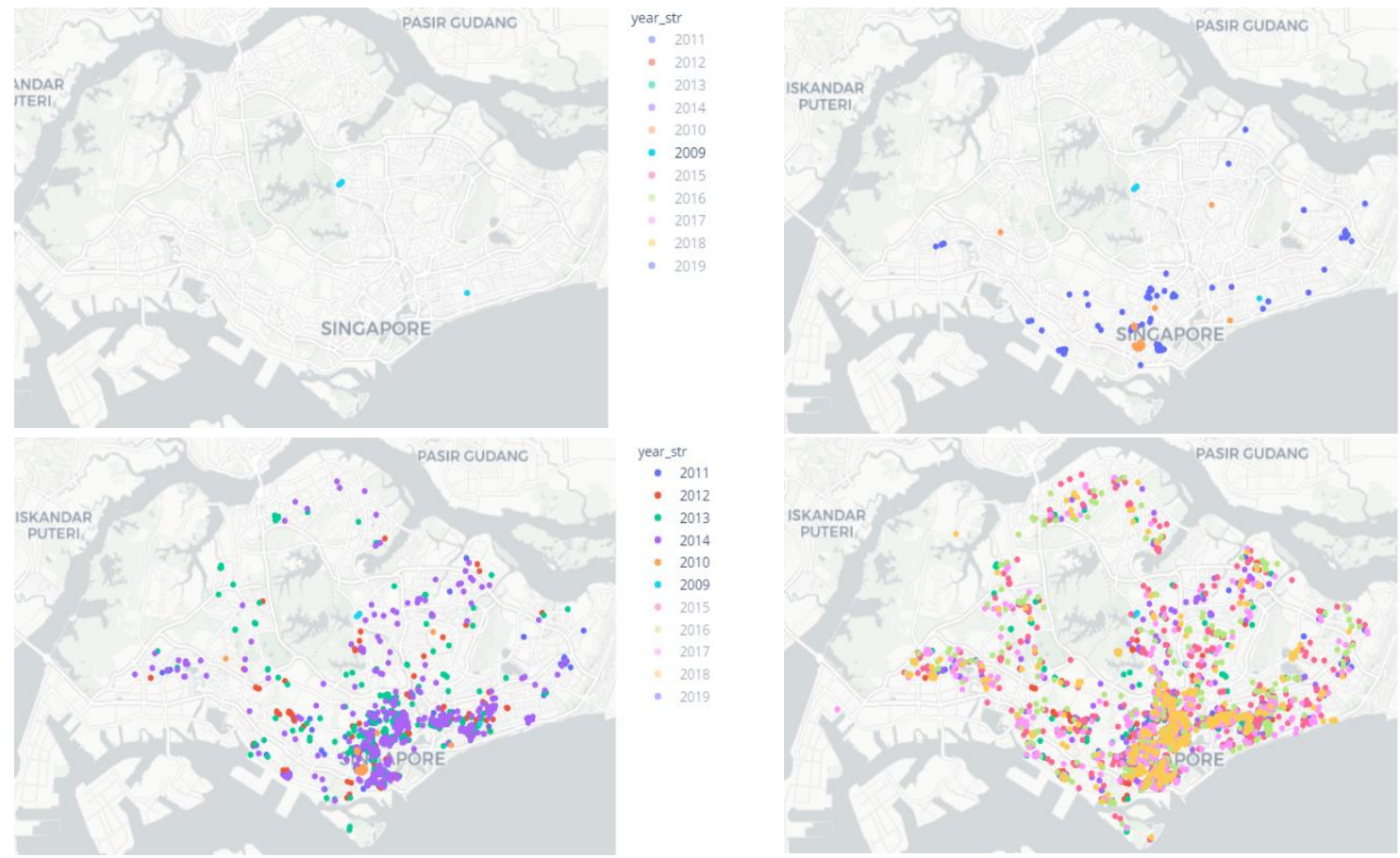

Gambar 5 Sebaran Properti Berdasarkan Tahun 

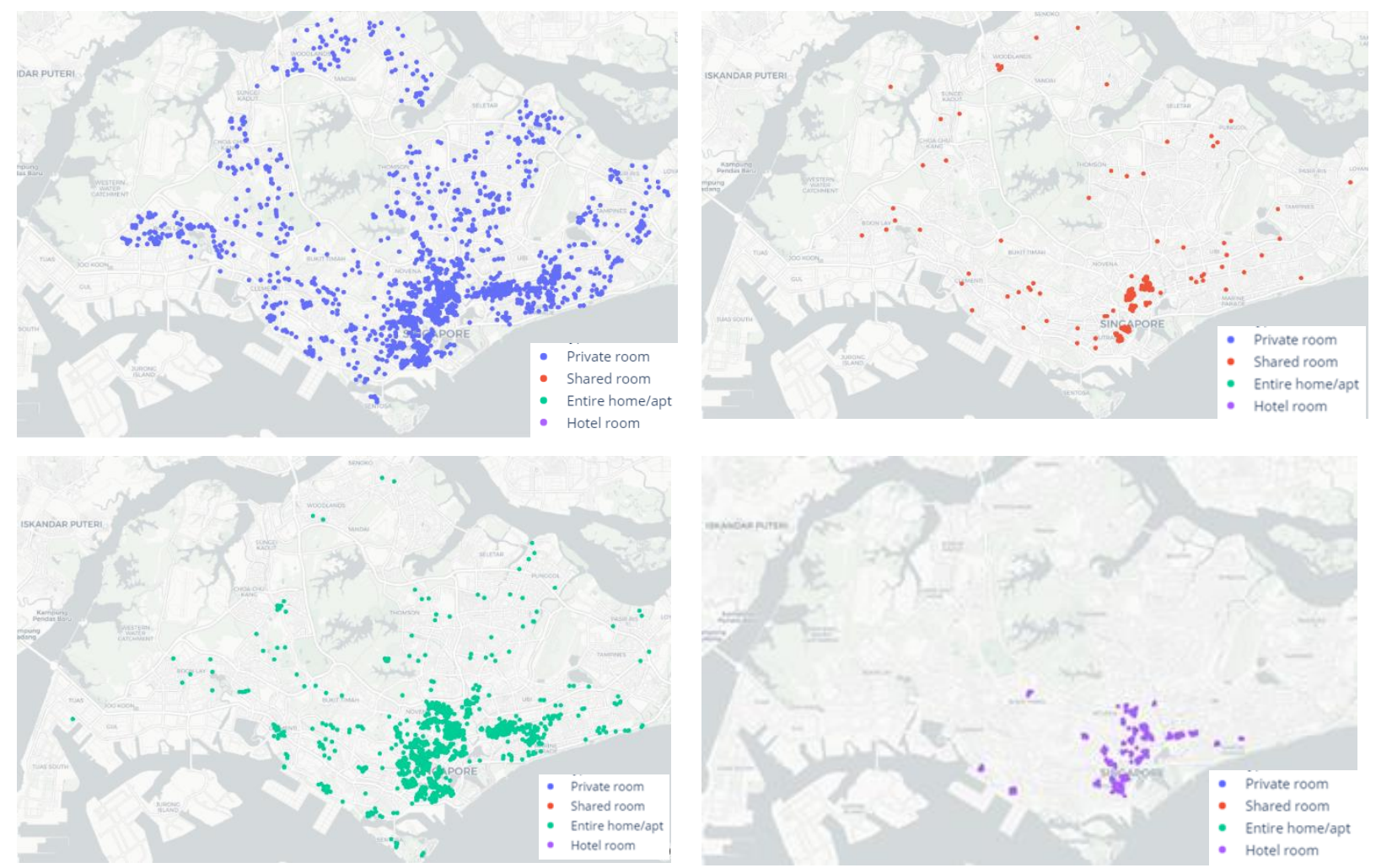

Gambar 6 Sebaran Properti Berdasarkan Tipe Ruangan

\section{Pembahasan}

Pola sebaran properti berpusat pada point of interest yang berupa tempat wisata. Central Region merupakan daerah yang memiliki tempat wisata paling banyak di Singapura. Hal ini tentunya menimbulkan permintaan tempat istirahat yang jauh lebih banyak dari wilayah yang lainnya.

Berkenaan dengan pola sebaran harga sewa, Central Region merupakan wilayah yang memiliki properti dengan harga sewa yang cukup mahal yaitu dengan rentang harga $\$ 6.000$ sampai $\$ 10.000$ per malam. Selain dekat dengan pusat wisata, jenis properti, luas, dan fitur properti yang ditawarkan menjadi faktor-faktor penentu tingginya harga sewa. Namun demikian, beberapa lokasi yang cukup jauh dari pusat wisata ada yang menawarkan harga sewa pada rentang harga yang sama.

Pada tahun 2009 hanya ada empat properti yang disewakan melalui platform Airbnb. Angka ini meningkat sangat drastis dan mencapai puncaknya pada tahun 2016 dengan tambahan sekitar 800 properti baru yang disewakan (lihat Gambar 7).

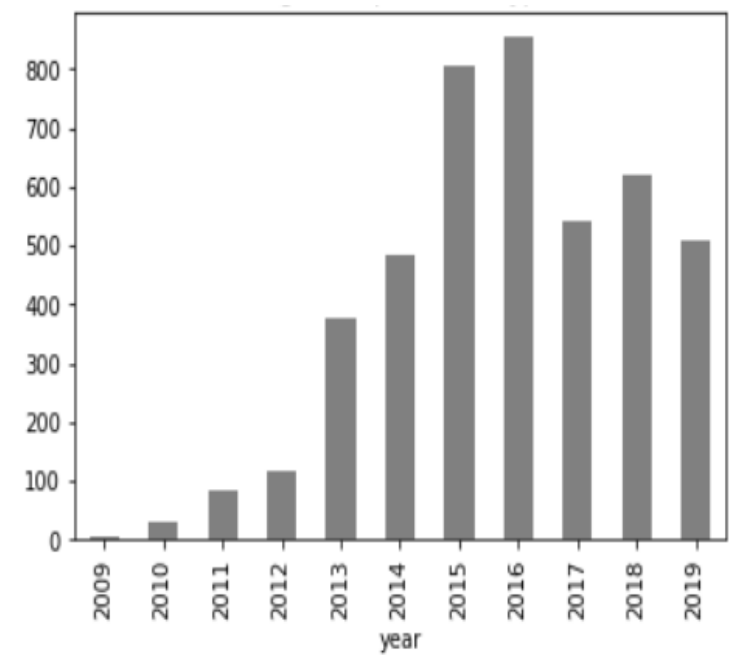

Gambar 7 Jumlah Properti per tahun

Terdapat empat tipe ruangan yang didefinisikan oleh Airbnb, yaitu private room, shared room, entire homelapartment, dan hotel room. Private room merupakan tipe ruangan yang paling banyak disewakan di semua wilayah yang ada, sedangkan ruangan bertipe hotel room adalah yang paling sedikit dan hanya ada di Center Region saja. Satu hal yang menarik adalah ruangan dengan tipe 
shared room lebih sedikit ditawarkan dibandingkan dengan entire home/apartment. Hal ini mungkin saja dipengaruhi oleh budaya masyarakatnya yang kurang nyaman berbagi ruangan di propertinya dengan orang asing.

\section{PENUTUP}

Pada penelitian ini telah dilakukan analisis sebaran properti, harga, dan tipe ruangan dengan menggunakan teknik analisis data secara visual. Telah dilakukan analisis menggunakan model visual untuk sebaran harga berdasarkan wilayah, sebaran harga sewa, sebaran properti berdasarkan tahun, dan sebaran properti berdasarkan tipe ruangan. Dari hasil yang didapatkan, dapat disimpulkan bahwa analisis data dengan menggunakan model visual, khususnya peta geografis, sangat membantu dalam menemukan pola-pola dan hubungan antar data.

\section{DAFTAR PUSTAKA}

Chen, Yi, Xiaoxiao Fu and Xinran Y. Lehto. 2016. "Chinese Tourist Vacation Satisfaction and Subjective Well-Being". Applied Research in Quality of Life 11: 49-64. <https://doi.org/10.1007/s11482-014-9354$\mathrm{y}>$.

$\mathrm{Gu}$, Yeong Hyeon, Seong Joon Yoo, Zhiyan Jiang, Yeo Jin Lee, Zhegao Piao, Helin Yin and Seogbong Jeon. 2018. "Sentiment Analysis and Visualization of Chinese Tourism Blogs and Reviews". In: . International Conference on Electronics, Information and Communication, ICEIC 2018. Institute of Electrical and Electronics Engineers Inc. 2018-January:1-4. <https://doi.org/10.23919/ELINFOCOM.20 18.8330589>.

Ioannides, Dimitri, Michael Röslmaier and Egbert van der Zee. 2019. "Airbnb as an Instigator of 'Tourism Bubble' Expansion in Utrecht's Lombok Neighbourhood". Tourism Geographies 21: 822-40. <https://doi.org/10.1080/14616688.2018.14 54505> [accessed 25 February 2020].
Lagonigro, Raymond, Joan Carles Martori and Philippe Apparicio. 2020. "Understanding Airbnb Spatial Distribution in a Southern European City: The Case of Barcelona". Applied Geography 115: 102136. <https://doi.org/10.1016/j.apgeog.2019.102 136>.

Li, Qiusheng, Yadong Wu, Song Wang, Maosong Lin, Xinmiao Feng and Haiyang Wang. 2016. "VisTravel: Visualizing Tourism Network Opinion from the User Generated Content". Journal of Visualization 19: 489502. <https://doi.org/10.1007/s12650-0150330-x>.

Wang, Dan, Mimi Li, Pengcheng Guo and Wenqing Xu. 2016. "The Impact of Sharing Economy on the Diversification of Tourism Products: Implications for Tourist Experience". In: . Information and Communication Technologies in Tourism 2016. Springer International Publishing. 683-94. <https://doi.org/10.1007/978-3319-28231-2_49>.

Wang, Dan and Juan L. Nicolau. 2017. "Price Determinants of Sharing Economy Based Accommodation Rental: A Study of Listings from 33 Cities on Airbnb.Com". International Journal of Hospitality Management 62: 120-31. <https://doi.org/10.1016/j.ijhm.2016.12.007 $>$.

Wang, Earo, Dianne Cook and Rob J Hyndman. 2020. "Calendar-Based Graphics for Visualizing People's Daily Schedules". Journal of Computational and Graphical Statistics, January, 1-28. <https://doi.org/10.1080/10618600.2020.17 15226> [accessed 1 March 2020].

Yeager, Emily Pauline, B. Bynum Boley, Kyle Maurice Woosnam and Gary T. Green. 2019. "Modeling Residents' Attitudes toward Short-Term Vacation Rentals". Journal of Travel Research, September, 004728751987025.

<https://doi.org/10.1177/004728751987025 5> [accessed 1 March 2020]. 